Copyright (C) 2014 by Academic Publishing House Researcher

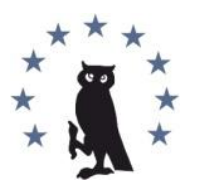

Published in the Russian Federation

European Researcher

Has been issued since 2010.

ISSN 2219-8229

E-ISSN 2224-0136

Vol. 84, No. 10-1, pp. 1752-1764, 2014

DOI: $10.13187 /$ er.2014.84.1752

www.erjournal.ru

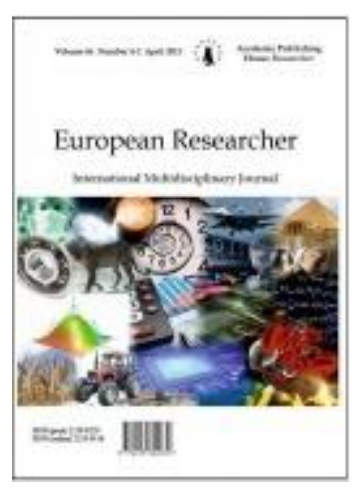

Economic sciences

Экономические науки

UDC 332.1

\title{
The Cyclicity of the Development of the Global Economic System amid Present-Day Globalization
}

\author{
${ }^{1}$ Mihail N. Dudin \\ ${ }^{2}$ Nikolaj V. Lyasnikov \\ 3 Aleksandr S. Senin \\ ${ }_{4}$ Sergej N. Kapustin
}

\begin{abstract}
${ }^{1}$ Russian Presidential Academy of National Economy and Public Administration
Prospekt Vernadskogo, 82, Moskva city, 119571

Dr. (Economy), Associate Professor

E-mail: dudinmn@mail.ru

${ }^{2}$ Russian Presidential Academy of National Economy and Public Administration

Prospekt Vernadskogo, 82, Moskva city, 119571

Dr. (Economy), Professor

3 Russian Presidential Academy of National Economy and Public Administration

Prospekt Vernadskogo, 82, Moskva city, 119571

Dr. (Economy), Professor

4 Russian Presidential Academy of National Economy and Public Administration

Prospekt Vernadskogo, 82, Moskva city, 119571

Dr. (Economy), Professor
\end{abstract}

\section{Abstract}

The relevance of this topic is associated with the diversity of causes behind crisis processes in economics and the individuality of each particular crisis. This necessitates classifying them in a detailed fashion.

The present downturn is a manifestation of the cyclicity of the development of the global economic system amid present-day globalization and the established architecture of the institutional space. The formal (legislation, contractual rules, corporate norms, etc.) and nonformal institutes (rules, customs, traditions, behavior as a whole, etc.), undergoing changes in their structure and mechanisms, caused the emergence of financial innovations whose yield surpassed that of the real sector of the economy multifold. This facilitated the concentration of money in financial markets and transforming them into a thing-in-itself.

The theory of economic cycles is one of the theories of economic dynamics which explain the movement of the national economy. While the theory of economic growth explores factors and 
conditions for growth as a long-term trend, the theory of cycles deals with causes behind fluctuations in economic activity through time.

Results. In accordance with the aims of this study, the authors established that crises can have the following causes: objective, which are associated with the cyclical development of the system, modernization and restructuring needs, and the impact of external factors, and subjective, which reflect errors in management, shortcomings in the organization of production, and the imperfections of innovation and investment policy. A crisis can take its course manifestly and be easily detected or can be inconspicuous and take its course in a latent form. The most dangerous are crises that affect the system as a whole. In a situation of this kind, there forms a train of complex issues resolving which depends on the timeliness of detecting them and professionalism in managing the organization, municipal education, and the state.

Keywords: cyclicity; globalization; global economic system; economic crises; classifying crises; causes behind the emergence of crises.

\section{Введение}

Циклическое развитие присуще как экономике в целом, так и ее отдельным отраслям. Она свойственна и многим иным процессам в природе и обществе. Свой жизненный цикл имеют даже товары. Цикличность в экономике, как и в других сферах, отражает неустойчивость развития, переход от одной экономической конъюнктуры к другой, от менее совершенной структуры производства к более совершенной, от одного уровня эффективности экономики к другому, от одной доли экстенсивных факторов к другой, от одной степени удовлетворения потребностей к более высокой. Это все формы отражения экономической конъюнктуры, которые могут рождаться не только по восходящей, но и по нисходящей линии. Наиболее яркий пример - движение экономики по фазам цикла. От кризиса, через депрессию и оживление, к подъему и обратно.

Кризисные явления сопровождали человечество на протяжении всего его исторического развития и всегда становились фактором, испытывающим его жизнеспособность. Кризисы свидетельствуют о наличии разбалансированности, уязвимых сторон, острых противоречий в функционировании системы [19].

В зарубежной экономической литературе принято считать цикл от подъема до подъема, которым завершается период роста и экономика вступает в фазу рецессии, спада или кризиса. Это все названия, отражающие разные этапы в зависимости от уровня сокращения объемов производства. Если рецессия - отсутствие положительной динамики, то спад уже характеризуется отрицательной динамикой, а кризис в экономике есть её крушение.

Экономический цикл в своем развитии проходит несколько стадий (фаз). Основное требование, которое накладывается при этом, заключается в том, что во время действия в экономике той или иной фазы должны происходить определенные схожие по логике и динамике процессы. Следовательно, разделение на фазы необходимо для того, чтобы подробно изучить соответствующие группы состояний экономического неравновесия, в том числе и действующие в рамках этих состояний базовые экономические связи. Практика показывает, что данное разделение оправдано. Развитие цикла отражается динамикой соответствующих экономических показателей, именно по поведению последней авторы разъединяют цикл на фазы. Как правило, цикл представлен в виде синусоиды вокруг положения равновесия [18].

В графическом виде цикл состоит из верхней и нижней полуокружностей, каждую из которых также можно разделить на две части, а их, в свою очередь, еще на две. Следовательно, получаются восемь попарно симметричных точек относительно точки равновесия: верхняя - нижняя, два положения равновесия и четыре промежуточные точки. При разграничении фаз обычно используются названные точки, причем их количество равняется количеству фаз. Наиболее часто применяется четырехфазный цикл.

Представляется, что надо исходить из следующих позиций:

1) кризис - исходная и определяющая фаза цикла;

2) он привносит факторы, способствующие выходу из него;

3) кризис временно разрешает всю совокупность противоречий, которые породили его, а затем (после выхода из кризиса) начинается новый этап их постепенного обострения; 
4) но совершается это уже на обновляемой материально-технической базе, когда противоречия вновь вызревают на этой новой базе в преддверии очередного кризиса.

В современном научно-философском знании кризис (с греч. krisis - исход сомнительной ситуации, решение по какому-либо вопросу) принято понимать как кратковременный переломный период в естественном процессе развития, способный дать спонтанное разрешение трудной ситуации, благоприятное изменение, разрешение серьезных проблем и стать исходной точкой принципиально нового этапа существования и развития системы, в рамках которой имел место кризис. В качестве таких систем могут выступать структуры самого различного рода и уровня: сознание индивида и группы, экономические, политические, технологические системы и т. д.

Большинство современных авторов в вопросе о причине цикла указывают, что чередование процветания и депрессии вызвано целым рядом факторов и, возможно, не всегда одним и тем же сочетанием их. Зачастую теории различных авторов отличаются не столько перечисляемыми причинами и условиями циклов, сколько различным значением, придаваемым тем или иным факторам. [14]

\section{Результаты исследования и их обсуждение}

На сегодняшний день проблемы экономических циклов достаточно широко отражены в исследованиях экономистов. Причем часто авторы обнаруживают и описывают свой, уникальный вид цикла. Вследствие чего определено достаточно большое количество разнообразных циклов. Для того чтобы представить системно все их многообразие, необходимо провести классификацию циклов. Определение видов циклов позволяет выдвинуть гипотезу существования некоторых из них в развитии российской экономики.

Циклы подразделяются в зависимости от длительности или периода на сезонные (год), краткосрочные (от трех до пяти лет, например, цикл Китчина), среднесрочные (от семи до двенадцати лет - Жуглара), циклы длительного периода (порядка двадцати лет - Кузнеца) и долгосрочные (более сорока лет). Последние циклы делятся на полувековые (длинные волны Кондратьева), вековые, тысячелетние и суперколебательные. [5]

По своему характеру циклы также могут быть природно-экологическими, демографическими, научно-техническими, технологическими и экономическими. Как уже говорилось выше, циклы подразделяются на жизненные и экономические. Эти два вида циклов характеризуются различными типами происходящих в них динамических процессов: эволюционные, необратимые, и волнообразные, обратимые.

Кроме того, экономические циклы делятся в соответствии с их объектом. В данном случае классификация циклов и кризисов имеет общий признак - область экономической деятельности. Отметим, что наиболее широко изучены промышленные циклы. Циклы, как и кризисы, бывают конъюнктурными и структурными, последние обусловлены структурными диспропорциями в экономике и носят, как правило, затяжной характер.

Среди российских учёных на вопрос о главной фазе цикла существуют иные воззрения. Такой фазой считается кризис. Данное понимание надо считать более правильным, поскольку в этой фазе заложены факторы, толкающие экономику к выходу из этого состояния. От ныне применяемых антикризисных мер зависит скорость выхода из кризиса, темпы последующего роста, его продолжительность, эффективность, конкурентоспособность, а в конечном счёте и высота самого подъёма (пика) экономики. [23]

Ларионов И. по причинам возникновения выделяет циклические, закономерные и случайные кризисы. Отсюда он делит кризисы на труднопрогнозируемые (как правило, вызванные внешними и случайными причинами: войнами, эпидемиями, природными катаклизмами) и относительно прогнозируемые кризисы. По возможностям преодоления кризисов он выделяет преодолимые самостоятельно, преодолимые с внешней помощью, непреодолимые. [8]

Классификация экономических кризисов, разработанная известным российским ученым в области цикличности Ю.В. Яковцом учитывает три вида: функциональный, временной, пространственный. [22]

Данную классификацию можно назвать интегральной. 
По сфере действия различаются кризисы воспроизводственные, структурные, инвестиционные, технологические, финансовые, кредитно-денежные, ценовые, в занятости и доходах населения.

По длительности - сезонные, краткосрочные, среднесрочные, долгосрочные, сверхдолгосрочные. Кризисы разной длительности накладываются друг на друга, вызывая резонансный, демпфирующий (смягчающий), либо деформирующий эффект.

По пространству - точечные (на одном предприятии), локальные (в пределах одного города), региональные, национальные (поражающие экономику одного государства), цивилизационные (охватывающие экономику стран одной цивилизации) и глобальные, поражающие всю мировую экономику. Выделение кризисов по пространственному признаку имеет очень важное значение для анализа причин их возникновения и особенностей протекания.

Характеры протекания глобальных кризисов и кризисов внутри национальной экономической системы имеют качественное различие. Первые охватывают все страны, вхождение в кризисную ситуацию может обуславливаться не внутренними причинами, а заданными извне. Антикризисное регулирование глобальных кризисов довольно затруднительно, т.к. требует координации усилий правительств различных стран неслучайно в результате глобального финансово-экономического кризиса 2008-2009 гг. формат встреч глав государств из «большой восьмерки» (G8) преобразовался в «большую двадцатку» (G20). Возможности отдельных стран в преодолении глобальных кризисов ограничены, особенно могут страдать зависимые, более слабые, малые экономики, важное значение приобретают над правительственные и международные экономические организации. Экономические кризисы стали приобретать мировой характер уже к середине XIX века, а сегодня роль глобальных кризисов резко усилилась в результате глобализационных процессов, роста открытости экономик и т.д. Кризисы внутри национальной экономической системы имеют эндогенные причины, носят цивилизационный оттенок, их преодоление в значительной степени зависит от грамотной антикризисной политики, проводимой национальными правительствами, которая может быть более или менее независимой. [22]

Существует ряд других критериев, по которым можно классифицировать экономические кризисы. Оригинальную классификацию экономических кризисов предлагают К. Рогофф и К. Рейнхарт. Они делят кризисы на две большие группы - кризисы, определяемые количественными порогами, и кризисы, определяемые событиями. К первым относятся инфляционные кризисы, крах валюты и девальвация валюты. Ко вторым относятся банковские кризисы, и внешние и внутренние дефолты. [15]

Очевидным недостатком данной классификации является упор на финансовую составляющую кризисов. Причины ищутся в сфере обмена, денежного обращения, психологии людей, неправильной экономической политике, т.е. носят субъективный характер. При этом кризисы, вызванные глубинными причинами (технологическая динамика, изменения в структуре производства и др.) остаются за рамками внимания.

Современная классификация экономических кризисов представлена на рис. 1. 

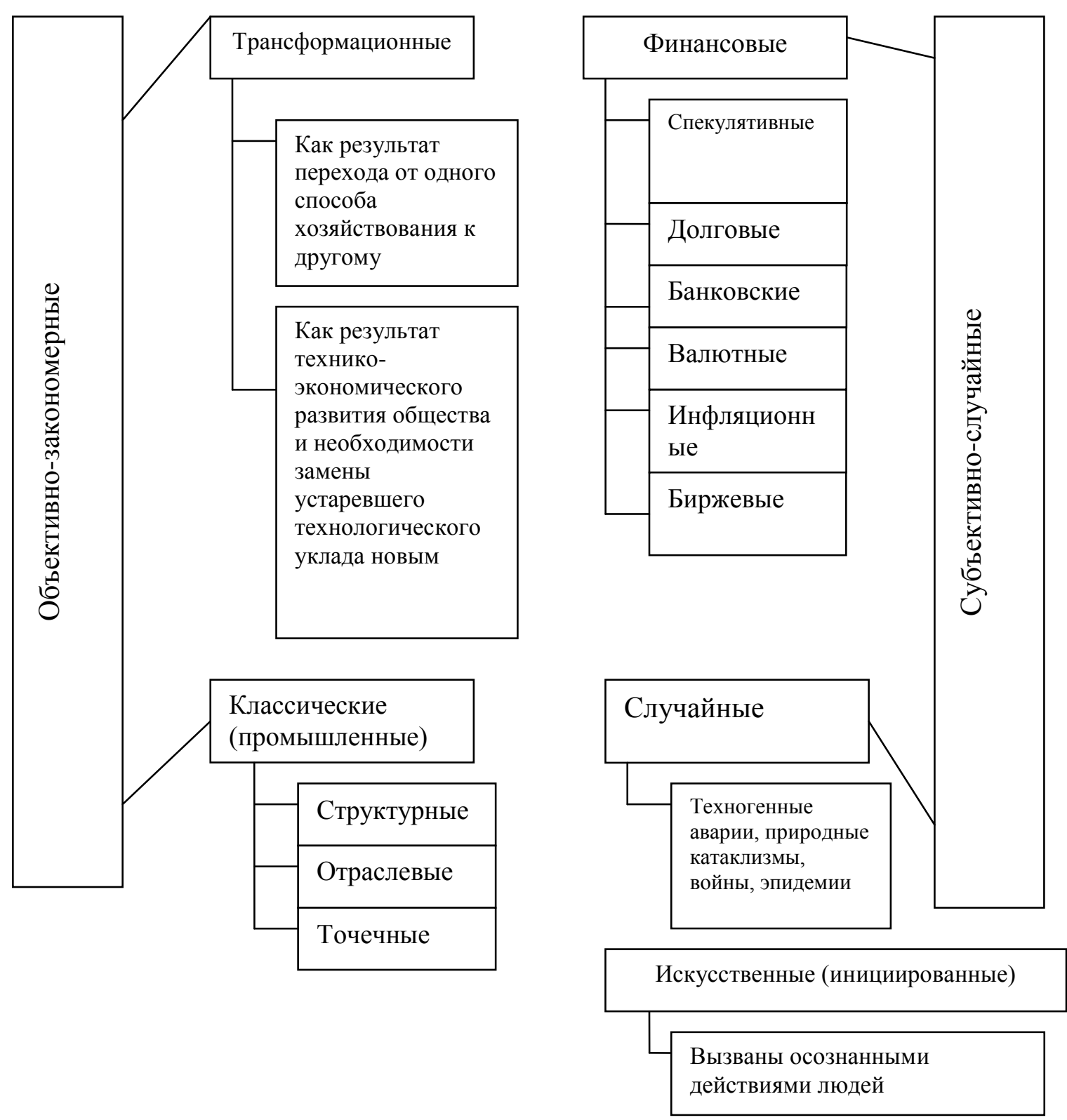

Источник: составлено по данным[7]

Puc. 1. Современная классификация экономических кризисов

Анализ экономических кризисов, механизмов их зарождения, особенностей и закономерностей протекания, а также существующих классификаций позволяет разделить все кризисы в экономике на две большие группы - объективно-закономерные и субъективно-случайные. В их рамках можно выделить пять видов экономических кризисов: трансформационные, классические (промышленные), финансовые, случайные и искусственные (инициированные). В основе объективно-закономерных кризисов лежат фундаментальные изменения в реальном секторе, они носят циклический характер, слабо зависят от воли людей, однако, в силу довольно четких закономерностей хорошо прогнозируемы. В эту группу входят трансформационный и промышленный кризисы.

Субъективно-случайные кризисы, как правило, носят внециклический характер, могут быть одномоментными, разовыми и больше не повториться в такой же форме в истории, их зарождение и течение может быть незакономерным, слабо - или средне прогнозируемым. В основе лежат случайные факторы (в основном, природные), непредсказуемое поведение людей, их психология, характерны для сферы обращения. В эту группу входят финансовые, случайные и искусственные кризисы. 
При исследовании потрясений конца XVIII и начала XIX вв. обращает на себя внимание постепенное расширение круга предприятий и отраслей, охватываемых процессом перепроизводства. Так, если от кризиса 1788 г. пострадало только несколько десятков хлопкопрядильных фабрик, то события 1819 г. поразили все возникшие к этому времени крупные фабрично-заводские центры английской хлопчатобумажной, шерстяной, металлургической и других отраслей промышленности. Разница между этими кризисами отражает большой путь развития фабричной системы за данный период, пройденный индустриальным лидером того времени Англией. Вместе с ростом механической промышленности постепенно совершался переход от локальных, частичных кризисов местного и отраслевого значения к общим кризисам, поражающим все важнейшие отрасли производства и влекущим глубокое потрясение всей экономики. Завершился этот переход, когда количественные изменения переросли в новое качество и разразился первый кризис общего перепроизводства 1825 г.

Вторая четверть XIX в. была отмечена европейскими буржуазными революциями 1848 г., а также открытием крупных месторождений золота в Калифорнии и Австралии. Огромный спрос со стороны золотоносных районов на различные виды товаров дал мощный толчок росту товарного производства на европейском континенте. Обильный приток в экономику нового золота, извлекаемого при существенно более низких производственных затратах, вызвал тенденцию к росту цен и величины прибавочной стоимости.

Следует отметить, что условия для кризисов формировались в Великобритании, промышленность которой значительно опережала другие страны. Англия была сердцем мирового хозяйства, определявшим биение пульса на периферии. Это было обусловлено всей предшествовавшей историей ее экономического развития, eе ролью в мировой экономике XVII и XVIII вв.

Географическое положение Англии на великом торговом пути из Европы в Америку благоприятствовало расцвету ее мореплавания и торговли. Революция середины XVII в. расчистила поле для дальнейшего роста английского капитализма, явилась мощным фактором ускорения его развития. Уже в конце XVII в. Англии принадлежало первенство в морском судоходстве и морской торговле. Тогда же были заложены основы ее будущего колониального могущества.

В указанном процессе особо следует выделить ряд инновационных «прорывов» XVIII в., обобщенно называемых «промышленной революцией», которая позволила Великобритании окончательно оставить позади основных конкурентов и почти на столетие занять передовые позиции в мировой экономической системе. В подъемах и кризисах первой половины XIX в. центральная роль принадлежала текстильной промышленности, которая первой вступала и в фазу подъема, и в фазу кризиса. За ней следовала тяжелая промышленность, подъем которой базировался, в большей части, на процессах расширения основного капитала легкой индустрии. К тому же удельный вес тяжелой промышленности был столь невысок, что она не могла играть решающей роли в смене фаз цикла.

Серьезным испытанием для мировой экономики стала Великая депрессия 19291933 гг., ознаменовавшая важный этап в развитии мирового хозяйства и продемонстрировавшая исчерпанность классической модели «стихийного рыночного хозяйства» с характерными для нее регулярно повторявшимися кризисами перепроизводства. Хотя внешне кризис выглядел лишь как очередное нарушение баланса между предложением и спросом, новизна ситуации характеризовалась масштабностью и остротой потрясений, а также быстрой передачей кризисных явлений из центра на периферию мировой хозяйственной системы, из сферы экономики в политику и идеологию.

Последствия Великой депрессии мировая экономика ощущала вплоть до 1939 г., отмеченного высоким военно-инфляционным спросом в преддверии новой войны, что позволяет некоторым исследователям считать 1930-е гг. в целом периодом длительной депрессии мирового хозяйства, начавшейся в 1929 г., а прерванный мобилизационным спросом кризис 1938 г. ее составной частью.

Существует несколько точек зрения о причине финансового кризиса 2008 г., но каждая из них аргументируется какой-либо одной причиной. Одни экономисты считают, что причиной явились международные потоки капитала или денежно-кредитные политики, 
другие, что причиной явилась жилищная политика, третьи, что было недостаточное регулирование банковского сектора, или жадность тех, кто функционировал в финансовом секторе и имел политическое влияние в Вашингтоне. [16]

В любом случае эти аргументы, если они используются в качестве единственного объяснения, являются слишком упрощенными и неполными. В то время как все эти факторы, несомненно, служат важными причинами кризиса, каждого из них недостаточно в качестве автономного объяснения.

Подход большинства других экспертов, которые пытаются объяснить кризис, страдает от противоположной проблемы - он слишком широкий. [2]

Не все, что пошло не так во время финансового кризиса, вызвало кризис, и в то время как некоторые причины были существенными, другие имели лишь незначительное воздействие. Не каждое изменение, связанное с жилищной системой или финансовой системой до кризиса, было причиной кризиса.

Также слишком упрощенной является гипотеза, что кризис вызван недостаточным регулированием, и противоположное мнение, что слишком сильное регулирование вызвало кризис. [1]

Возникновение кризиса не может быть мерой для определения эффективности регулирования. Финансовое регулирование необходимо для устранения конкретных сбоев в финансовой системе. Например, с высокой степенью риска нетрадиционное ипотечное кредитование небанковскими кредиторами процветало в 200о-х гг., но при неэффективном регулировании нанесло огромный ущерб и привело к финансовому кризису. Плохо разработанные государственные жилищные программы искажали ситуацию на рынке и внесли свой вклад в создание необоснованной ипотеки. Безответственное кредитование по всей стране и крупные убытки американской страховой корпорации AIG в условиях банкротства банка Lehman Brothers были частично связаны с неэффективным регулированием и надзором. В то время как неудачи ипотечных агентств FannieMae и FreddieМас были следствием государственной политики, они смешивали общественные цели с личной выгодой, что и привело к негативным последствиям. [25]

Большинство экспертов считают, что кризиса можно было избежать, если бы только Соединенные Штаты применили более строгое регулирование и надзор за финансовой деятельностью. Этот вывод в значительной степени игнорирует глобальный характер кризиса.

Кредитный пузырь появился не только в Соединенных Штатах, но и в Европе. Поэтому в объяснении причин кредитного пузыря следует сосредоточиться на факторах, общих для обоих регионов.

Кредитный пузырь проявился не только на рынке жилья, но и на рынке коммерческой недвижимости. Были мыльные пузыри в Великобритании, Испании, Австралии, Франции и Ирландии, причем некоторые даже более выражены, чем в Соединенных Штатах. Это говорит о том, что недостаточно было бы просто усилить регулирование на рынке жилья в США.

Многие финансовые учреждения в Исландии, Испании, Германии и Великобритании и других странах не делали ставку на жилищный рынок США, и в большинстве случаев они имели жесткое регулирование, тем не менее, также столкнулись с финансовыми неудачами, аналогичными тем, которые наблюдались в Соединенных Штатах. Эти факты говорят о том, что жилищная политика США сама по себе - неисчерпывающее объяснение кризиса. Объяснить финансовый и экономический кризис только недостаточным регулированием и надзором в Соединенных Штатах, игнорируя международные параллели, невозможно, поскольку не будут расставлены приоритеты в причинах и не будет достаточного обоснования причины и следствия.

Прежде чем выявить главные причины кризиса, опишем его основные этапы. Соединенные Штаты по-прежнему находятся на стадии экономического спада, вызванного финансовым кризисом, проявившемся в августе 2007 г. и закончившемся в начале 2009 г. Основными причинами, которые вызвали финансовый кризис, были финансовый шок в сентябре 2008 г. и сопутствующая ему финансовая паника. Финансовый шок и паника вызвали серьезный спад в кредитовании в четвертом квартале 2008 г. 
Некоторые экономисты описывают эту ситуацию как рецессию, которая началась в декабре 2007 г и продолжалось до июня 2009 г., и от которой только сейчас начинают восстанавливаться. Недавние события в США можно описать следующими этапами. [10]

Серия форшоков началась в августе 2007 г., продолжением был экономический спад, который длился по август 2008 г., когда проблемы с ликвидностью не удалось решить трем крупным финансовым институтам США. Серьезный финансовый шок в сентябре 2008 г., в котором десять крупных финансовых институтов изменили свои институциональные структуры. Конец финансового шока и паники - начало 2009 г. - точка отсчета финансового оздоровления и период восстановления в реальном секторе экономики.

В настоящее время экономика Соединенных Штатов по-прежнему нестабильна, их финансовая система все еще восстанавливается и перестраивается, пытается вернуться в стабильный и быстрый экономический рост. [3]

Можно назвать следующие внешние и внутренние факторы, которые имеют важное значение для объяснения причин возникновения финансово-экономического кризиса:

Кредитный пузырь. Начиная с конца 1990-х гг. Китай и другие крупные развивающиеся страны, а также крупные нефтедобывающие страны создали большие капитальные излишки, которые были инвестированы в финансовые рынки Соединенных Штатов и Европы, в результате чего процентные ставки стали падать. Кредитные спрэды сузились, а это означает, что стоимость заимствований для финансирования рискованных инвестиций снизилась. Кредитный пузырь образовался в Соединенных Штатах и Европе, наиболее заметным его проявлением было увеличение инвестиций в ипотечные кредиты с высоким риском. Монетарная политика США, возможно, способствовала образованию кредитного пузыря, но не вызывала его. Существуют три основных возможных объяснения кредитного пузыря: глобальные потоки капитала, переоценка риска и денежно-кредитная политика.

Жилищный пузырь. С конца 1990-х и в начале 2000-х годов образовался большой и устойчивый жилищный пузырь в США. Пузырь характеризовался значительным национальным ростом цен на жилье и быстрым региональным циклом бума-спада в Калифорнии, Неваде, Аризоне и Флориде. Многие факторы внесли свой вклад в формирование пузыря на рынке жилья, который, лопнув, вызвал огромные потери для домовладельцев и инвесторов. Связь между краткосрочными процентными ставками и ценами на жилье очень слабая, поэтому, даже если целью Федеральной резервной системы (ФРС) было снизить ставки кредитования между банками, это не может объяснить, почему ставки по тридцатилетним ипотечным кредитам были слишком низкими. [12]

Ипотечное кредитование. Имели место чрезмерно оптимистичные предположения о ценах на жилье в США, а также проблемы на первичном и вторичном рынках ипотечных кредитов. Рискованные ипотечные ссуды на триллионы долларов широко внедрялись через финансовую систему: связанные с ипотекой ценные бумаги собирались в пакеты, а затем из них образовывались другие пакеты ценных бумаг, и эти пакеты продавались инвесторам во всем мире. Когда пузырь лопнул, потери в сотни миллиардов долларов потрясли рынок, а также финансовые учреждения, которые приобрели значительное количество таких ипотечных ссуд и, используя их в качестве обеспечения, образовали много долгов. Это произошло не только в Соединенных Штатах, но и по всему миру. Эти потери были приумножены производными финансовыми инструментами, такими как синтетические ценные бумаги. [24]

Система ипотечной секьюритизации поставляла «токсичные» ипотечные ссуды с территорий всей Америки инвесторам во всем мире. Многие ипотечные кредиторы установили планку настолько низко, что просто принимали любые квалификационные характеристики заемщиков на веру, часто сознательно игнорируя уровень платежеспособности заемщика. Почти четверть всех ссуд, предоставленных за первую половину 2005 г., были кредитами с выплатой только процентов, а 68 \% ипотечных кредитов с плавающей ставкой и возможностью выбора размера платежей, предоставленных банками США, были оформлены без требования документов или с требованием ограниченного числа документов.

Финансовые учреждения целенаправленно увеличивали риск. Руководители многих крупных и средних финансовых учреждений в США сконцентрировали огромные 
накопления в высоко рискованных финансовых инструментах в форме облигаций, обеспеченных ипотечными кредитами. Некоторые пошли на это сознательно, сделав ставку на рост цен на жилье, в то время как другие уделили недостаточно внимания потенциальному риску. Это ускорило крах крупных финансовых институтов. Серьезнейшие провалы в корпоративном управлении, а также в управлении рисками во многих важнейших для функционирования всей системы финансовых учреждениях были ключевой причиной кризиса. Существовало мнение, что инстинкт самосохранения крупнейших финансовых фирм защитит их от фатально рискованных действий без необходимости постоянного вмешательства регулирующих органов, которое, как утверждали фирмы, приведет к удушению новаторства.

Слишком многие из этих учреждений действовали опрометчиво, принимая на себя слишком большой риск и имея слишком мало капитала и слишком большую зависимость от краткосрочного финансирования. Во многих отношениях это отражало фундаментальное изменение данных учреждений, в особенности крупных инвестиционных банков и банковских холдинговых компаний, в своей деятельности все больше сосредотачивавшихся на рискованных торговых операциях, приносивших немалую прибыль. Они предприняли огромные усилия для привлечения и поддержки ненадежных заемщиков, а также создавая связанные с ипотекой ценные бумаги, собирая их в пакеты ценных бумаг, а затем из них образовывая другие пакеты и продавая на триллионы долларов, включая синтетические финансовые продукты. Финансовые учреждения и рейтинговые агентства с энтузиазмом использовали математические модели как надежные инструменты предсказания риска, во многих случаях подменяя ими здравый смысл. Управление рисками слишком часто становилось оправданием рискованных действий.

Краткосрочное заимствование огромных сумм в сочетании с долговыми обязательствами, которые не видны другим участникам рыночных отношений, увеличили шансы быстрого распада системы. За последние тридцать с лишним лет произошел рост теневой банковской системы, непрозрачной и перегруженной краткосрочными займами, размеры которой конкурировали с размерами традиционной банковской системы. Когда жилищный и ипотечный рынки потерпели крах, то и недостаток прозрачности, и необычайная перегруженность долгами, и краткосрочное кредитование, и рискованные активы - все эти факторы проявились и внесли свой собственный вклад. Это вызвало панику. Одной из проблем была большая потеря жилья. Этот общий шок означал, что проблема была шире, чем один обанкротившийся банк, - ключевые крупные финансовые институты были капитализированы.

Финансовый кризис вызывает экономический кризис. Финансовый шок и паника вызваны большим сокращением производства и рабочих мест в реальном секторе экономики. Шок и паника закончились в начале 2009 г. Негативные последствия для реального сектора экономика продолжаются до сих пор.

\section{Заключение}

Для решения проблемы мирового финансового кризиса правительствам стран необходимо принять смешанную стратегию краткосрочных и долгосрочных мер. Также необходимы согласованные действия по всему миру, основанные на проведении аналогичных политик (денежно-кредитных экспансий), осуществляемых национальными правительствами. К таким действиям можно отнести следующие:

1. Возродить межбанковское кредитование, предоставляя временную гарантию на краткосрочное беззалоговое кредитование между регулируемыми организациями.

2. Центральный банк как посредник на межбанковских рынках является более дорогостоящим и менее эффективным.

3. Обеспечить надежное страхование для банковских депозитов.

4. Принять меры по рекапитализации банковской системы государственными средствами.

Процентные ставки центрального банка должны оставаться низкими. Банки должны иметь возможность оценить свои активы по их покупной цене, а не их текущей рыночной стоимости. Некоторые необходимые меры уже были предприняты, например национализация банков, но без международной координации они не эффективны. 
Также необходимо ослабить ожидания последующей рецессии, так как они оказывают вредное воздействие на потребительский спрос и инвестиционные расходы. Увеличение государственных расходов или снижение налогов не поможет восстановить доверие на данном этапе. Любой финансовый стимул должен быть своевременным, носить временный характер и быть направленным на тех, кто склонен тратить деньги, предоставленные правительством. Это вряд ли возможно в условиях нынешнего страха и недоверия к финансовым рынкам.

Необходимо восстановление финансовых систем и введение банковского союза в зоне евро, а также разработка и реализация подкрепляемых конкретными мерами действенных планов среднесрочной фискальной корректировки и реформы социальных пособий в Японии и США. Кроме того, необходимо увеличить потенциальный объем производства, в частности в зоне евро и Японии, в том числе посредством реформ, создающих равные условия для существующих и новых участников рынка труда и снижающих барьеры для выхода на рынки продукции и услуг. Еще одна задача состоит в том, чтобы осторожно изменять курс денежно-кредитной политики США с учетом меняющихся перспектив роста, инфляции и финансовой стабильности. Чрезмерное ужесточение может быть трудно впоследствии устранить, и мировой рост вполне может оказаться не выше, а ниже среднесрочных прогнозов роста и инфляции. Следует принимать меры для сохранения финансовой стабильности, учитывая риски, унаследованные от недавних кредитных бумов, и новые риски, вызванные потоками капитала. Многие страны нуждаются в новом раунде структурных реформ, включая инвестиции в государственную инфраструктуру, устранение барьеров для выхода на рынки товаров и услуг и в случае Китая - переориентацию роста с инвестиций на потребление. Тот факт, что финансовые рынки делают ставку на восстановление мировой экономики в течение ближайших двух лет, становится все более очевидным. Инвесторы отказались прислушаться к предупреждениям, что акции технологических компаний были сильно переоценены на рубеже тысячелетия. Глава Федеральной резервной системы США Бен Бернанке развеял идею, что ипотечный рынок США был несчастным случаем и что проблема с американской недвижимостью может иметь глобальные последствия.

\section{Выводы}

Динамика кризиса простирается от неспособности правительства решить стоящие перед обществом проблемы политическими методами до распада существующих политических структур. Можно выделить следующие этапы протекания общенационального кризиса.

1. Нарастание социального недовольства широких слоев населения из-за нерешенности социальных проблем и снижения уровня жизни. Отдельные классы, слои стремятся изменить свой статус в обществе. Невозможность удовлетворить социально типичные стандарты потребления вызывает у человека чувство неудовлетворенности жизнью

2. Раскол в правящих кругах (правительстве, парламенте), который обусловлен тем, что различные сегменты власти предлагают различные пути выхода из кризиса.

3. Резко падает авторитет властвующих институтов, так как проявляется их неспособность улучшить ситуацию, выполнять обязательства, обещания, адресованные обществу. Их опора становится колеблющейся и зыбкой.

4. Повышается политическая активность широких масс, которые, поняв тупиковость сложившейся ситуации, ищут свои пути выхода из кризиса и выдвигают политические требования.

5. Окончанием кризиса является переход к новой социальной системе или кардинальное переустройство существующей социальной системы.

\section{Примечания:}

1. Блант М. Финансовый кризис. М.: Астрель, 2008.

2. Брылёв Н.И. Сценарий развития мирового финансового кризиса. Этапы протекания экономического кризиса в России [Электронный pecypc]. URL: http://www.nbrilev.ru/krizisscenariy.htm/ 
3. Ершов М. Пять лет после масштабной фазы кризиса: насколько стабильна ситуация? //Вопросы экономики. 2013. № 12. С. 29-47.

4. Калашникова Т.В. Финансовый кризис: причины возникновения и возможные пути преодоления // Вестник Томского государственного университета. Экономика. 2014. № 1 (25). C. 93-103.

5. Кустова Л.С. Глобальный кризис и «длинные волны» Н.Д. Кондратьева в свете теории цикличности и современной синергетики // Медиаскоп. 2010. № 3. С. 13-13.

6. Лавров С.Ю. Макроэкономическая, технологическая и институциональная составляющие современного цикла мир-системы // Вестник Нижегородского университета им. Н.И. Лобачевского. 2012. № 5 (1). С. 236-241.

7. Лажевский Г.М. Особенности и источники кризисных процессов в современной экономике // Вестник Челябинского государственного университета. 2012. № 24. С. $20-24$.

8. Ларионов И.К. Антикризисное управление: учебное пособие. М.: Издательский дом «Дашков и К», 2010.

9. Малкина М.Ю., Лавров С.Ю. Институциональные причины цикличности экономического развития и особенности современного кризиса // Экономический анализ: теория и практика. 2011. № 40. С. 2-8.

10. Маслов О.Ю. Основные этапы текущего мирового кризиса [Электронный ресурс]. URL: http://www.polit.nnov.ru/2009/04/06/[5] gistcrisisetape13/

11. Митяев Д.А. О динамике саморазрушения мировой финансовой системы (сценарии и стратегии). Возможности адаптации и выбор стратегии для России. Сценарно-игровой доклад. М., 2009. С. 28.

12. Нуриэль Рубини. Пузырь на рынке недвижимости, или четыре признака катастрофы [Электронный pecypc]. - URL: http://www.e-xecutive.ru/ knowledge /announcement/1896265

13. Полтерович В.М. Гипотеза об инновационной паузе и стратегия модернизации // Вопросы экономики. 2009. № 6.

14. Порфирьев Б.Н. Экономический кризис: проблемы управления и задачи инновационного развития//Проблемы прогнозирования. 2010. № 5. С. 20-26.

15. Рейнхарт К.М., Рогофф К.С. На этот раз все будет иначе. Восемь столетий финансового безрассудства. М.: Карьера Пресс, 2011. С. 4.

16. Соколинский B.M., Бузулук Т.С. Финансовый кризис - феномен глобализации // Финансы и бизнес. 2009. № 1. С. 2-8. C. $7-8$.

17. Финансовый кризис в России и в мире / под ред. Е.Т. Гайдара. М.: Проспект, 2009.

18. Хаустова В.Е., Проноза П.В. Теоретические аспекты возникновения и развития кризисных явлений в экономике//Проблемы экономики (Харьков). 2011. № 4. С. 13-23.

19. Чекменёва Т.Г. Кризисы в общественном развитии: теоретический аспект//Вестник Воронежского государственного технического университета. 2010. Т. 6. № 12. С. 103-106.

20.Щербаков Г.А. Ретроспективный обзор причин и последствий макроэкономической нестабильности//Экономика и управление: проблемы, решения. 2014. № 1. С. 16-27.

21. Яковец Ю.В. Пять ответов ученых на вызовы кризисов// Партнерство Цивилизаций. 2013. №3.

22. Baranenko S.P., Dudin M.N., Ljasnikov N.V., Busygin K.D. Using environmental approach to innovation-oriented development of industrial enterprises// American Journal of Applied Sciences. 2013. Vol. 11, No.2, P. 189-194.

23. Dudin M.N., Lyasnikov N.V., Yahyaev M.A., Kuznetzov A.V. The organization approaches peculiarities of an industrial enterprises financial management // Life Science Journal. 2014. Vol. 11, No.9, P. 333-336.

24. European Central Bank 2009: Financial Stability Review (June 2009) [Electronic resourse]. URL: http://www.ecb.int/pub/pdf/other/financialstabilityreview200906en.pdf

25. Keith Hennessey, Douglas Holtz-Eakin, Bill Thomas. Causes of the financial and economic crisis [Electronic resourse]. - URL: http://fcic-static.law.stanford.edu/cdn_media/fcicreports/fcic_final_report_hennessey_holtz-eakin_thomas_dissent.pdf 


\section{References:}

1. Blant M. Financial crisis. M: Astrel, 2008.

2. Brylev N.I. Scenario of development of the world financial crisis. Stages of proceeding economic crisis in Russia [Electronic resource]. URL: http://www.nbrilev.ru/krizisscenariy.htm/

3. Ershov M. Five years after large-scale phase of the crisis: how stable is the situation? // Questions of economy. 2013. № 12.

4. Kalashnikov T.V. Financial crisis: causes and possible ways of overcoming//Herald of Tomsk state University. Economy. 2014. № 1 (25).

5. Kustova P.S. Global crisis and "long wave" N Kondratieff in the light of the theory of cyclical and modern synergetics//Mediascope. 2010. № 3 .

6. Lavrov H.E. Macroeconomic, technological and institutional components of the modern cycle of the world-system// Bulletin of the NizhniyNovgorodUniversity. N.I. Lobachevsky, 2012, issue 5 (1).

7. Lazhevskij G. M. Special Features and sources of crisis processes in the modern economy / Year M. Lazevski // Bulletin of the Chelyabinsk state University. 2012. № 24. S. 20-24.

8. Larionov I.K. Crisis management: a training manual. M: Publishing house "Dashkov and K, 2010.

9. Malkina M.Ju., Lavrov S.Ju. Institutional causes of recurrence of economic development and features of the current crisis // the Economic analysis: theory and practice. 2011. № 40.

10. Maslov O.Y. the Main stages of the current global crisis [Electronic resource]. - URL: http://www.polit.nnov.ru/2009/04/06/[5] gistcrisisetape13/

11. Mityaev D.A. About the dynamics of self-destruction of the world financial system (scenarios and strategies). Adaptation options and the choice of strategy for Russia. Scenario-'s report. M., 2009.

12. Nurijel' Rubini. The bubble in the property market, or four signs of catastrophe [Electronic resource]. - URL: http://www.e-xecutive.ru/knowledge/announcement/1896265

13. Polterovich V.M. the innovation pause Hypothesis and the strategy of modernization // Questions of economy. 2009. № 6.

14. Porfir'ev B.N. Economic crisis: problems of management and tasks of innovative development//problems of forecasting. 2010. № 5 .

15. Rejnhart K.M., Rogoff K.S This time everything will be different. Eight centuries of financial folly. M: Career Press, 2011.

16. Sokolinskij V.M., Buzuluk T.S. Financial crisis - the phenomenon of globalization // Finance and business. 2009. № 1 .

17. The financial crisis in Russia and in the world, Ed. ET Gaidar. M.: Prospect, 2009. p. 7-8.

18. Haustova V.E., Pronoza P.V. Theoretical aspects of the appearance and development of crisis phenomena in the economy//economic Problems (Kharkiv). 2011. № 4.

19. Chekmenjova T.G.Tthe current YEAR, the Crisis in social development: theoretical aspect // Vestnik of Voronezh state technical University. 2010. So 6. № 12.

20. Shcherbakov G.A. Retrospective review of the causes and consequences of macroeconomic instability//Economics and management: problems, solutions. 2014. № 1 .

21. Yakovets Y.U. Five answers scientists to the challenges of the crisis// the Partnership of Civilizations. 2013. №3.

22. Baranenko S.P., Dudin M.N., Ljasnikov N.V., Busygin K.D. Using environmental approach to innovation-oriented development of industrial enterprises// American Journal of Applied Sciences. 2013. Vol. 11, No.2, P. 189-194.

23. Dudin M.N., Lyasnikov N.V., Yahyaev M.A., Kuznetzov A.V. The organization approaches peculiarities of an industrial enterprises financial management // Life Science Journal. 2014. Vol. 11, No.9, P. 333-336.

24. European Central Bank 2009: Financial Stability Review (June 2009) [Electronic resourse]. URL: http://www.ecb.int/pub/pdf/other/financialstabilityreview200906en.pdf

25. Keith Hennessey, Douglas Holtz-Eakin, Bill Thomas. Causes of the financial and economic crisis [Electronic resourse]. - URL: http://fcic-static.law.stanford.edu/cdn_media/fcicreports/fcic_final_report_hennessey_holtz-eakin_thomas_dissent.pdf 
УДК 332.1

\title{
Цикличность развития мировой экономической системы в условиях современной глобализации
}

\author{
${ }^{1}$ Михаил Николаевич Дудин \\ 2 Николай Васильевич Лясников \\ 3 Александр Сергеевич Сенин \\ ${ }^{4}$ Сергей Николаевич Капустин
}

\begin{abstract}
${ }^{1}$ Российская академия народного хозяйства и государственной службы при Президенте Российской Федерации, Российская Федерация

119571, Москва, проспект Вернадского, 82, строение 1

Доктор экономических наук, доцент

E-mail: dudinmn@mail.ru

${ }^{2}$ Российская академия народного хозяйства и государственной службы при Президенте Российской Федерации, Российская Федерация

119571, Москва, проспект Вернадского, 82, строение 1

доктор экономических наук, профессор

3 Российская академия народного хозяйства и государственной службы при Президенте

Российской Федерации, Российская Федерация

119571, Москва, проспект Вернадского, 82, строение 1

доктор экономических наук, профессор

4 Российская академия народного хозяйства и государственной службы при Президенте Российской Федерации, Российская Федерация

119571, Москва, проспект Вернадского, 82, строение 1

доктор экономических наук, профессор
\end{abstract}

Аннотация. Актуальность выбранной темы обусловлена многообразием причин кризисных процессов в экономике, индивидуальностью каждого отдельного кризиса. В связи с этим возникает необходимость их подробной классификации.

Настоящий кризис - это проявление цикличности развития мировой экономической системы в условиях современной глобализации и сформировавшейся архитектуры институционального пространства. Формальные институты (законодательство, контрактные правила, корпоративные нормы и т. п.) и неформальные институты (правила, обычаи, традиции, поведение в целом и т. д.), претерпевая изменения в собственной структуре и механизмах, вызывали появление финансовых инноваций, доходность по которым кратно превышала доходность, получаемую в реальном секторе экономики. Это способствовало концентрации денег на финансовых рынках и превращению их в вещь в себе.

Теория экономических циклов относится к теориям экономической динамики, которая объясняет движение народного хозяйства. Если теория экономического роста исследует факторы и условия роста как долговременной тенденции, то теория цикла - причины колебаний экономической активности во времени.

Результаты. В рамках изложения представленной статьи авторами было установлено, что причины кризиса могут быть: объективными - связанными с циклическим развитием системы, потребностями модернизации, реструктуризации, воздействием внешних факторов, и субъективными отражающими ошибки в управлении, недостатки в организации производства, несовершенство инновационной и инвестиционной политики. Кризисы могут протекать явно и легко обнаруживаться, а могут быть малозаметными и идти в скрытой форме. Наиболее опасны кризисы, затрагивающие систему в целом. В такой ситуации образуется вереница сложных проблем, решение которых зависит от своевременности их выявления и профессионализма в управлении организацией, муниципальным образованием, государством.

Ключевые слова: Цикличность; глобализация; мировая экономическая система; экономические кризисы; классификация кризисов; причины возникновения кризисов. 